\title{
Guest editors introduction to the special issue on service and manufacturing innovations in e-business platforms
}

\author{
Fujun Lai ${ }^{1} \cdot$ Xin Robert Luo ${ }^{2}$
}

Published online: 21 June 2016

(C) Springer Science+Business Media New York 2016

Electronic commerce has deeply transformed industries and markets over the past two decades, and continues to generate new service and manufacturing innovations. Our special issue of Electronic Commerce Research showcases new research on the technological, economic, managerial, and behavioral aspects of this transformation in services and manufacturing, bringing together six interdisciplinary articles offering novel insights into electronic commerce. QueryWe lead off with a study on the important, but academically under-researched, area of feminist consumer behavior. Liao, et al.'s “Factors Affecting Female User Information Adoption” found quality and source credibility to be of primary importance for this demographic. We follow with a study by Che et al. "Characteristics of Online Group-Buying Website and Consumers Intention to Revisit," that identifies website-specific features of richness, timeliness, and inconsistency as significant factors in customer revisit and repurchase decisions. Subjective assessments of "trust" are increasingly of interest in behavioral studies of e-markets. Ke et al. describe in "Online Trust-Building Mechanisms for Existing Brands" providing new evidence that trust-building in e-markets is synonymous with brand-building. Linking and leveraging existing customer bases is an old strategy in marketing, but takes new forms in electronic commerce. Pee's "Customer co-creation in B2C e-commerce" reviews empirical evidence on the impact of customer co-creation, finding in the information age that idea co-creation has a significantly stronger impact on commercial success than decision co-creation. Yang et al. "Exploring Continued Use of Mobile Shopping Channel in China" compares China's

Fujun Lai

fujun.lai@usm.edu

1 University of Southern Mississippi, Hattiesburg, USA

2 University of New Mexico, Albuquerque, USA 
experience in the lucrative mobile market, emphasizing the aspects in which experience in the fastest growing Internet economy in the world differ from other significant markets. Our final paper in this special issue explores optimal channel structures in e-commerce. Wang et al. in "Optimal Distribution Channel Strategy for New and Remanufactured Products" present models that will find value in e-marketing businesses seeking to balance operations and minimize costs in servicing their customers. This issue of Electronic Commerce Research has offered us an exceptional opportunity to showcase new research in an exciting and changing field. We hope you share our enthusiasm for this research, and enjoy the articles published in our special issue.

Fujun Lai is McCarty Distinguished Professor of MIS and Decision Sciences and Professor of Management in the College of Business at the University of Southern Mississippi, USA. He received his $\mathrm{Ph} . \mathrm{D}$. from the City University of Hong Kong. His research interests include e-commerce, enterprise information systems, supply chain and logistics management. His work on these topics has been published in Journal of Operations Management, Decision Sciences, Communications of the ACM, Decision Support Systems, IEEE Transactions on Engineering Management, Journal of Strategic Information Systems, and among others.

Xin (Robert) Luo is an Endowed Regent's Professor and Associate Professor of MIS and Information Assurance in the Anderson School of Management at the University of New Mexico, USA. He received his Ph.D. in MIS from Mississippi State University, USA. He has published research papers in leading journals including Communications of the ACM, Decision Sciences, Decision Support Systems, European Journal of Information Systems, Journal of the AIS, Journal of Strategic Information Systems, Information Systems Journal, Information \& Management, and Computers \& Security, etc. He is currently serving as an Ad-hoc Associate Editor for MIS Quarterly and an Associate Editor for Decision Sciences, European Journal of Information Systems, Electronic Commerce Research, Journal of Electronic Commerce Research, and International Conference on Information Systems. He is an Editor in Chief for International Journal of Information and Computer Security and International Journal of Accounting and Information Management. His research interests center around information assurance, innovative technologies for strategic decision-making, and global IT management. 